LAWRENCE LIVERMORE NATIONAL LABORATORY

\title{
DPAL: A New Class of Lasers for CW Power Beaming at Ideal Photovoltaic Cell Wavelengths
}

W. F. Krupke, R. J. Beach, S. A. Payne, V. K. Kanz, and J. T. Early

September 15, 2003

$2^{\text {nd }}$ International Symposium on Beamed Energy Propulsion, Sendai, Japan, October 20-23, 2003 


\section{Disclaimer}

This document was prepared as an account of work sponsored by an agency of the United States Government. Neither the United States Government nor the University of California nor any of their employees, makes any warranty, express or implied, or assumes any legal liability or responsibility for the accuracy, completeness, or usefulness of any information, apparatus, product, or process disclosed, or represents that its use would not infringe privately owned rights. Reference herein to any specific commercial product, process, or service by trade name, trademark, manufacturer, or otherwise, does not necessarily constitute or imply its endorsement, recommendation, or favoring by the United States Government or the University of California. The views and opinions of authors expressed herein do not necessarily state or reflect those of the United States Government or the University of California, and shall not be used for advertising or product endorsement purposes. 


\title{
DPAL: A new class of lasers for $\mathrm{cw}$ power beaming at ideal photovoltaic cell wavelengths
}

\author{
W. F. Krupke, R. J. Beach, S. A. Payne, V. K. Kanz, J. T. Early \\ Lawrence Livermore National Laboratory \\ University of California \\ 7000 East Avenue, Livermore CA 94550
}

\begin{abstract}
The new class of diode pumped alkali vapor lasers (DPALs) offers high efficiency cw laser beams at wavelengths which efficiently couple to photovoltaic (PV) cells: silicon cells at $895 \mathrm{~nm}$ (cesium), and GaAs cells at $795 \mathrm{~nm}$ (rubidium) and at $770 \mathrm{~nm}$ (potassium). DPAL electrical efficiencies of $25-30 \%$ are projected, enabling PV cell efficiencies $\sim 40 \%$ ( $\mathrm{Si}$ ) and $\sim 60 \%$ (GaAs). Near-diffractionlimited DPAL device power scaling into the multi-kilowatt regime from a single aperture is projected.
\end{abstract}

\section{OPTIMUM LASER WAVELENGTH AND WAVEFORM}

\section{Laser Power Beaming Applications}

Several valued applications of laser power beaming have been identified and assessed during the past decade. These applications include the transfer of groundgenerated laser power to remote PV cells placed on: 1) the lunar surface for colony power [1]; 2) GEO satellites for battery recharging during spring/fall equinoxes $[2,3,4]$; 3) LEO satellites for orbital maneuvers and transfers [5,6]; 4) space elevators to supply power to climbers [7,8]; 5) various DOD platforms/applications [9]. Several systems analyses and subsystem and components assessments have also been performed to identify optimum operating parameters for key elements of these applications $[4,10,11]$. A dominant driver in these analyses is the spectral and temporal response functions of practical PV converter cells, based primarily on the mature technology base of silicon ( $\mathrm{Si}$ ) and gallium arsenide (GaAs) PV cells.

\section{Optimum Laser Wavelength}

Fig. 1 shows the spectral dependence of PV conversion efficiency of Si, GaAs and other semiconductor materials [12]. The long-wavelength threshold for excitation of a silicon PV cell is $\sim 1100 \mathrm{~nm}$, rises to a peak conversion efficiency of $\sim 40 \%$ at a wavelength of $\sim 900 \mathrm{~nm}$, and drops to half-peak conversion efficiency at a wavelength of $\sim 500 \mathrm{~nm}$. It is known that silicon PV cells exposed to electron bombardment characteristic of the GEO environment are damaged in a manner that decreases the PV efficiency and shifts the spectral response curve to shorter wavelengths. Thus, the optimum operating wavelength of a laser power beaming source employing silicon PV 
cells is $\sim 900 \mathrm{~nm}$ (if the silicon PV cells will not be subjected to damaging electron irradiation); the optimum wavelength shifts to $\sim 770 \mathrm{~nm}$ when such damage is anticipated.

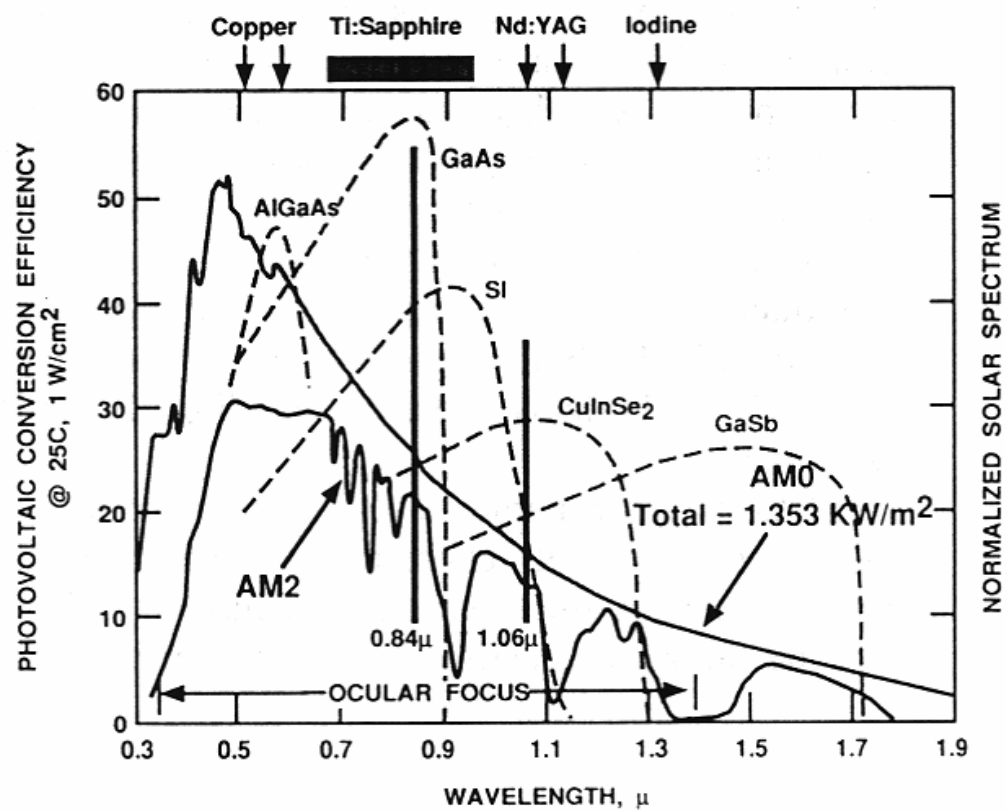

FIGURE 1. Spectral response of photovoltaic cells (after ref. 12).

The GaAs PV cell exhibits a long-wavelength excitation threshold of $\sim 910 \mathrm{~nm}$, rises to a peak conversion efficiency of $\sim 60 \%$ at a wavelength of $\sim 850 \mathrm{~nm}$, and drops to half-peak conversion efficiency at a wavelength of $\sim 300 \mathrm{~nm}$. Thus, for GaAs PV cells, the optimum source wavelength is $\sim 850 \mathrm{~nm}$, but a source operating wavelength of $\sim 800 \mathrm{~nm}$ will not result in a significantly lower efficiency.

\section{Optimum Laser Temporal Waveform}

Solar cells are designed to operate under steady continuous-wave (CW) solar illumination. Illumination for the cell produces useful electric power proportional to the photocurrent, while producing a dissipative power loss proportional to the square of the photocurrent (due to the cell's internal resistance). For a specified illumination intensity, the cell is designed to maximize conversion efficiency. When illuminated by a repetitively pulsed source with a given peak to average intensity, the dissipative power loss increases relative to useful power generated, thus lowering the cell conversion efficiency. The degree to which efficiency decreases depends strongly on the peak-to-average power of the rep-pulsed source, the characteristic time duration of the pulses, and the internal response time of the cell photoelectrons $[10,13,14]$. Simulations of $\mathrm{Si}$ and GaAs photovoltaic cell responses to pulsed waveforms have been carried out [15] and correlated with measurements of cell performance under 
pulsed illumination. In summary, these studies show that: 1) cell performance degrades significantly for sources generating long pulses ( $>25 \mathrm{nsec})$ at low duty factors $(<0.001)$; 2) cell performance may degrade incrementally for sources generating short pulses $(<100$ psec) at high duty factor $(>0.1)$; and 3$)$ the optimum power beaming source temporal waveform is continuous wave $(\mathrm{CW})$.

\section{Previously Considered Lasers For Power Beaming}

Several well-developed lasers have been considered as potential sources for power beaming applications [16], including Nd:YAG (1064 nm), frequency-doubled $\mathrm{Nd}$ :YAG $(532 \mathrm{~nm})$, copper vapor $(510 \mathrm{~nm})$, titanium sapphire $(690-1100 \mathrm{~nm})$, AlGaAs laser diode arrays $(\sim 810 \mathrm{~nm})$. Of these, the Nd:YAG based lasers generally have ineffective wavelengths for matching practical photovoltaic cells. The copper vapor not only has a poor wavelength match but also operates with a pulse duration ( $\sim 40 \mathrm{nsec})$ and duty factor $\left(\sim 10^{-4}\right)$ that would significantly degrade photovoltaic conversion efficiency. The titanium sapphire (TiS) laser is tunable from $\sim 690 \mathrm{~nm}$ to $\sim 1000 \mathrm{~nm}$ and well matches the response curves of both GaAs and Si. However, the TiS laser cannot be directly pumped with high performance semiconductor laser diode pumps, and to date there has been no attempt to scale the output power of the TiS laser above about 100 watts. The concept of directly using high power AlGaAs laser diode arrays operating at a wavelength near $810 \mathrm{~nm}$ has been suggested, but attempts to scale diode array power while achieving near-diffraction-limited beam quality has been elusive.

The rf-linac-driven free-electron-laser (FEL) has been most aggressively assessed for power beaming applications [9-12]. Under development for two decades, the pace of FEL development has been relatively slow (compared to the characteristic development time of solid state and gas lasers) because FELs generally require a significant investment in facility infrastructure even for low power exploratory experimentation. In the US, FEL development has gained accelerated momentum in recent years due to the development of superconducting magnets and accelerator infrastructure as a core part of a National DOE program at the Jefferson National Laboratory.

The rf-linac-based FEL typically produces low peak power pulses with pulse durations in the psec range, with operating duty factors up to $10^{-1}$. Tests of both Si and AlGaAs PV cells with this type of waveform indicate little degradation in conversion efficiency. While rf FEL sources may be the ultimate high power (MW class source) for certain power-beaming applications, it seems that there is a need for continuous wave laser sources operating at optimum wavelengths capable of efficiency generating $100 \mathrm{~kW}$ level near-diffraction-limited output in physically-compact form factors. A new class of diode-pumped alkali lasers (DPALs) has been invented that generally provides this set of characteristics [17-19]. 


\section{DIODE-PUMPED ALKALI LASER (DPALS) CONCEPT}

As a class, the neutral alkali vapor atoms ( $\mathrm{Li}, \mathrm{Na}, \mathrm{K}, \mathrm{Rb}$, and $\mathrm{Cs}$ ) manifest the same rather simple low-lying electronic structure, due to their possession of but a single valance s-electron. This electron gives rise to a ${ }^{2} \mathrm{~S}_{1 / 2}$ ground level and to ${ }^{2} \mathrm{P}_{1 / 2}$ and ${ }^{2} \mathrm{P}_{3 / 2}$ first and second excited levels split by a relatively small energy due to spin-orbit interaction. For illustrative purposes here we use the rubidium atom whose energy levels are shown in Fig. 2. The spectroscopic properties of the electric-dipole allowed ${ }^{2} \mathrm{~S}_{1 / 2}-{ }^{2} \mathrm{P}_{1 / 2}$ and ${ }^{2} \mathrm{~S}_{1 / 2}{ }^{2} \mathrm{P}_{3 / 2}$ resonance transitions (the so-called $\mathrm{D}_{1}$ and $\mathrm{D}_{2}$ transitions, respectively) of the alkali atoms have been extensively studied. Also studied in detail are the collisional effects of all of the rare-gases and selected molecular gases on the population kinetics of ${ }^{2} \mathrm{P}_{1 / 2,3 / 2}$ excited alkali atoms, including spectral broadening of the D-transitions, collisional mixing rates of excited ${ }^{2} \mathrm{P}_{1 / 2,3 / 2}$ alkali atoms, and inelastic quenching rates.

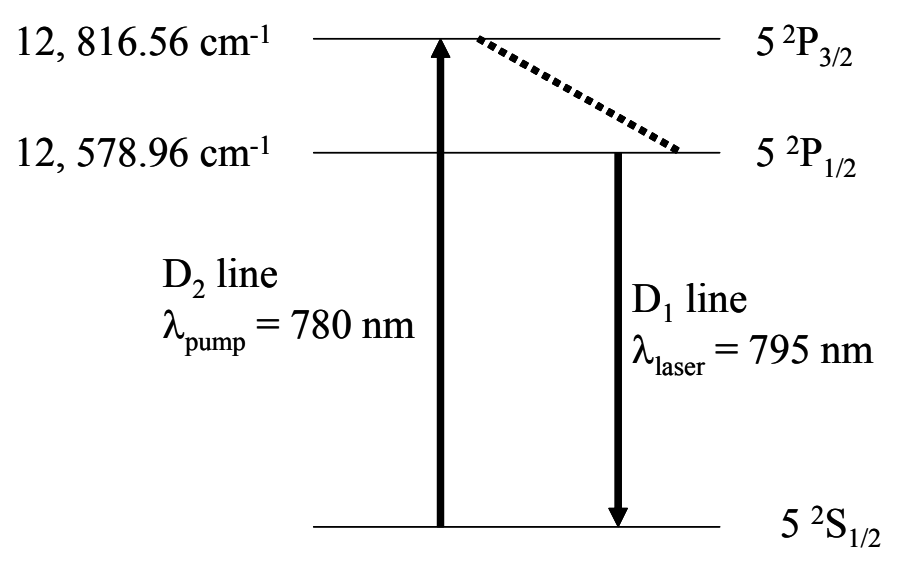

FIGURE 2. Energy level diagram of atomic $\mathrm{Rb}$ indicating pump and laser transitions.

Because of the relatively small quantum energy defects between $D_{1}$ and $D_{2}$ transitions $(2 \%$ for $\mathrm{Rb})$, the neutral alkali atoms have the potential to be especially efficient laser species in three-level lasers, provided practical means can be devised for effectively pumping the $\mathrm{D}_{2}$ transition [19]. For efficient three-level laser action to be achieved using alkali atoms pumped by commercial multimode diode pump laser sources with spectral widths of several $\mathrm{nm}$, several conditions need be met simultaneously. First, the $\mathrm{D}_{1}$ and $\mathrm{D}_{2}$ transitions must be collisionally broadened sufficiently to assure that these transitions are effectively spectrally homogeneous to pump and induced $\mathrm{D}_{1}$ laser radiation. This can be achieved by buffering the alkali vapor with a partial pressure of one or more atmospheres of a rare gas such as helium. Second, the relatively broad spectrum of a practical pump source must be efficiently absorbed by the relatively narrow alkali $\mathrm{D}_{2}$ pump transition (even when it has been 
collisionally broadened). This can be achieved by adopting an end-pumped laser geometry, which effectively increases the spectral opacity of the medium in the far wings of the collisionally-broadened spectrally homogeneous $\mathrm{D}_{2}$ transition, and therefore increases pump absorption efficiency. Third, population excited to a ${ }^{2} \mathrm{P}_{3 / 2}$ level by the pump must be rapidly quenched to the ${ }^{2} \mathrm{P}_{1 / 2}$ upper laser level at a rate that is much faster than ${ }^{2} \mathrm{P}$ spontaneous emission rates of $\sim 3 \times 10^{7} \mathrm{sec}^{-1}$. Collisional mixing of the ${ }^{2} \mathrm{P}_{1 / 2,3 / 2}$ levels at rates an order of magnitude greater than this can be achieved by buffering the alkali vapor with $\sim 100$ Torr partial pressure of a small molecule such as ethane. When these three conditions are simultaneously met, one can anticipate efficient three-level laser action on the first resonant $\mathrm{D}_{1}$ transitions of the alkali atoms.

Table 1 lists for the potassium, rubidium, and cesium alkali vapors the $\mathrm{D}_{2}$ pump wavelengths, the $\mathrm{D}_{1}$ laser wavelengths, and quantum energy defects. These alkalis are of particular interest because they can all be pumped with mature laser diode arrays utilizing $\mathrm{AlGaAs}$ and InGaInP compound semiconductor material systems. From Table 1, we see that these three DPALs are well matched to the range of optimum wavelengths for laser power beaming applications: Si (Cs at $895 \mathrm{~nm}$ ), GaAs (K at 770 $\mathrm{nm}$ or $\mathrm{Rb}$ at $785 \mathrm{~nm}$ ). Because these lasers emit on the $\mathrm{D}_{1}$ transitions of the alkali atoms DPALs are perfect sources for remote powering of alkali-vapor-based photothermal engines $[20,21]$ as well as photovoltaic power converters.

TABLE 1. DPAL quantum defects, and pump and laser wavelengths

\begin{tabular}{|l|c|c|c|}
\hline Alkali Atom & Pump Wavelength (nm) & Laser Wavelength (nm) & Quantum Defect \\
\hline K, potassium & 766 & 770 & 0.0044 \\
\hline Rb, rubidium & 780 & 785 & 0.019 \\
\hline Cs, cesium & 852 & 895 & 0.047 \\
\hline
\end{tabular}

Recently we reported CW TEM $_{00}$ laser action at $795 \mathrm{~nm}$ on the $\mathrm{D}_{1}$ transition of rubidium, using a titanium sapphire pump laser as a surrogate for a diode pump. The spectral width of the TiS pump was about four times broader than the collisionally broadened $\mathrm{D}_{2}$ pump transition $[17,18]$. We modeled the end-pumped geometry utilized in this laser demonstration experiment using the methodology developed by Beach [22] for $\mathrm{CW}$ end-pumped quasi-three-level lasers such as Yb:YAG. We took the ${ }^{2} \mathrm{P}_{1 / 2,3 / 2}$ mixing rate to be fast compared to all other rates present, consistent with literature data. That is, we assumed the population densities in the $5^{2} \mathrm{P}_{1 / 2}$ state and the $5^{2} \mathrm{P}_{3 / 2}$ state to be in thermal equilibrium at the local gas temperature. We assume plane waves for the pump and laser beams within the resonator, and spectrally convolve the broader spectrum of the pump with the narrower Lorentzian pump transition of the alkali vapor along the cell, taking into account depletion of the ground level and the spectral reshaping of the pump beam as it propagates through the absorbing atomic vapor. We obtained excellent quantitative lock-up with the code using literature spectroscopic and kinetic data.

Using this benched-marked model we have modeled end-pumped DPAL systems in which the pump freely propagates through a vapor cell as shown in Fig. 3. In this approach, a hollow lens-duct is used to deliver the pump light to the laser cell in a way 
that is compatible with both the use of a geometrically unstable resonators, and the desire to let the pump light double pass the gain medium to improve pump absorption efficiency. Based on preliminary modeling, we believe the DPAL concept described above scales gracefully to systems with output powers beyond $100 \mathrm{~kW}$, with very high efficiency. As an example, Fig. 4 plots optical-optical efficiency of a Rb DPAL versus output coupler reflectivity for several pump irradiance levels using the same 10 cm long cell described above.

The optimized operating parameters for the three cases plotted in Fig. 4 are summarized in Table 2, where it is seen that the optimized $\mathrm{Rb}$ number density increases as the pump irradiance increases. From the results summarized in Table 2, it is clear that a $100 \mathrm{~kW}$ class DPAL will be characterized by a laser output area of approximately 10 square centimeters.

TABLE 2. Optimized Rb DPAL systems using 10 atm of He and 2 nm pump diodes

\begin{tabular}{|c|c|c|c|c|}
\hline $\mathbf{I}_{\text {pum p }}$ & $\begin{array}{c}\text { Optimized Rb } \\
\text { density } \bullet \text { cell length }\end{array}$ & $\begin{array}{c}\text { Rb Cell } \\
\text { temperature }\end{array}$ & $\begin{array}{c}\text { Optimized output } \\
\text { coupler } \\
\text { reflectivity }\end{array}$ & $\begin{array}{c}\text { Optical-optical } \\
\text { efficiency }\end{array}$ \\
\hline $10 \mathrm{~kW} / \mathrm{cm}^{2}$ & $3.94 \times 10^{14} / \mathrm{cm}^{2}$ & $142^{\circ} \mathrm{C}$ & 0.54 & 0.41 \\
\hline $25 \mathrm{~kW} / \mathrm{cm}^{2}$ & $6.90 \times 10^{14} / \mathrm{cm}^{2}$ & $150^{\circ} \mathrm{C}$ & 0.35 & 0.58 \\
\hline $40 \mathrm{~kW} / \mathrm{cm}^{2}$ & $9.75 \times 10^{14} / \mathrm{cm}^{2}$ & $154^{\circ} \mathrm{C}$ & 0.23 & 0.65 \\
\hline
\end{tabular}

\section{Diode Pumped Alkali Gas (Vapor) Laser with unstable resonator}

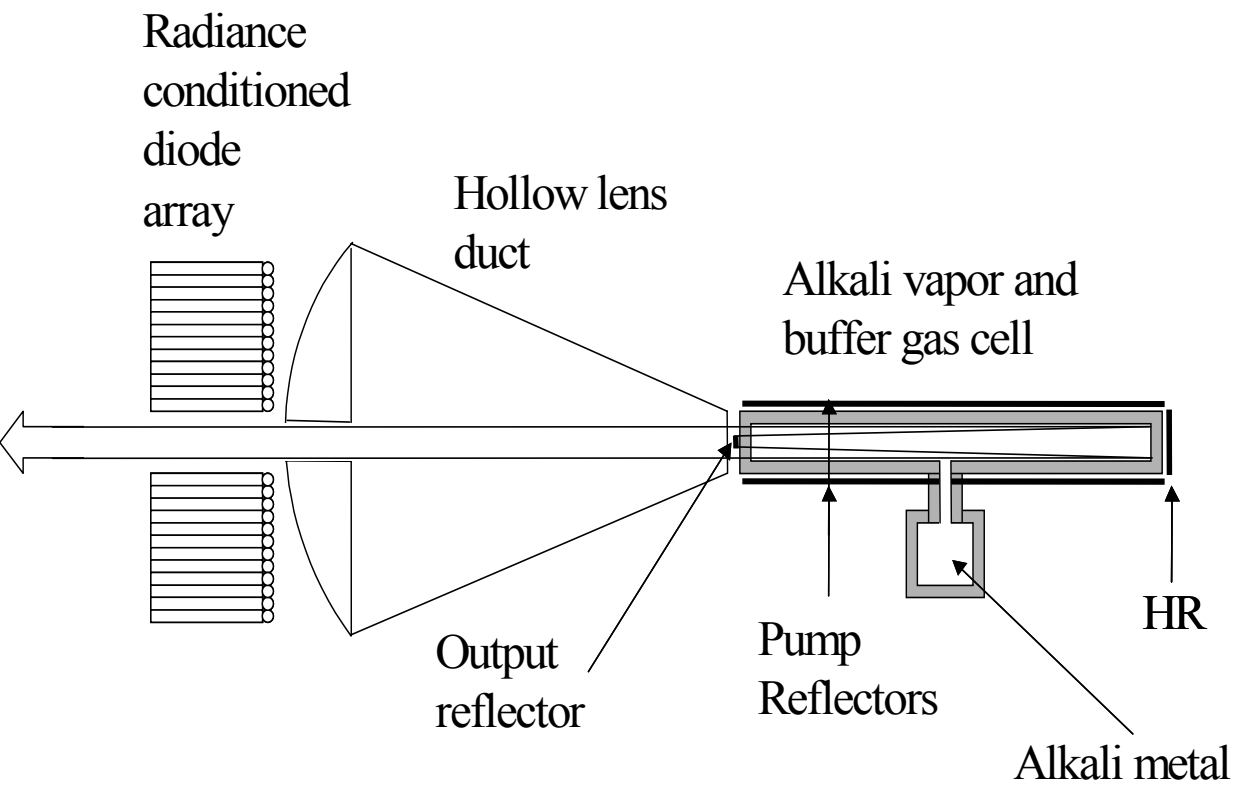

FIGURE. 3 Concept for a power scaled Rb DPAL system 


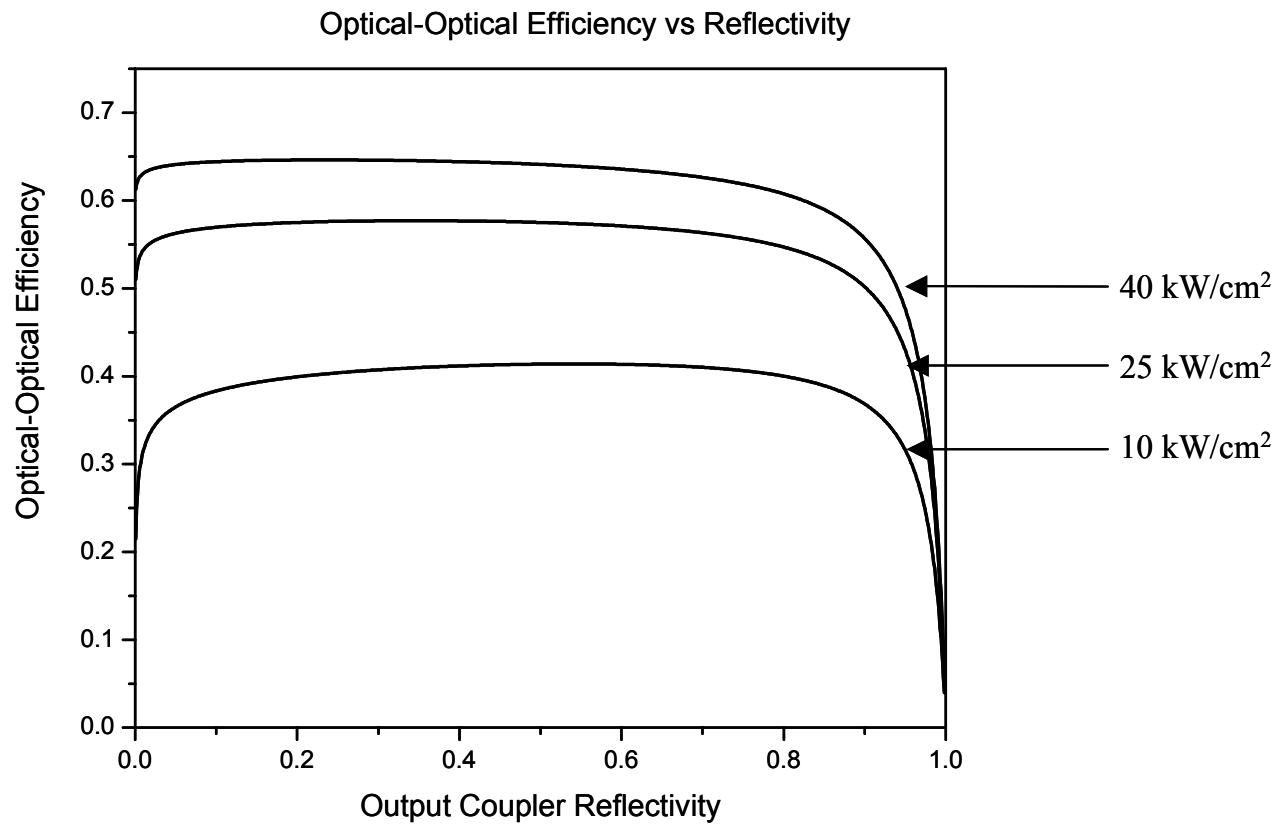

FIGURE. 4 Optical-optical efficiency for a Rb DPAL at three different levels of incident pump irradiance as a function of the output coupler reflectivity.

In addition to demonstrating near $70 \%$ optical-optical efficiency using an initial pump irradiance of $40 \mathrm{~kW} / \mathrm{cm}^{2}$, well within the reach of today's power scaled and radiance-conditioned laser diode arrays, the plots in Fig. 4 with their high efficiencies maintaining at low reflectivities underscore the compatibility of the DPAL concept with unstable resonators. With optical-optical efficiencies peaking near output coupler reflectivities of 0.2 , strip unstable resonators with cavity magnifications of 3 are reasonable choices for extracting with good beam quality over extended apertures.

An interesting device configuration for a $100 \mathrm{~kW}$ class DPAL is analogous to that presently utilized for commercial multi-kW seal-off, 2-D waveguide $\mathrm{CO}_{2}$ lasers, shown in Fig. 5. In this architecture, high pressure helium gas $(\sim 10 \mathrm{~atm})$ conducts waste heat generated in the optically pumped alkali vapor gain medium to the near-by large top and bottom cell plates, which are water cooled on their outer surfaces. In this way, there is no need to flow the working alkali-buffer gas laser medium. 


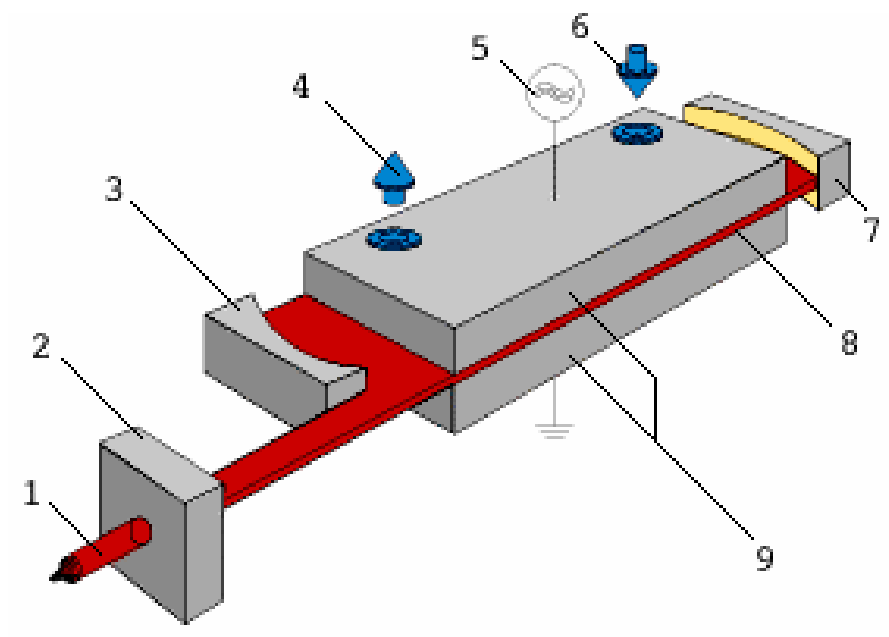

FIGURE. 5 Geometry of a high power $\mathrm{CO}_{2}$ sealed off waveguide laser. In a high power DPAL the rf discharge pumping is replaced by $2-\mathrm{D}$ diode array pumping with the use of a cylindrical hollow lens duct.

In order to limit the temperature gradient between the large cell plates and the center plane to a practical value of $\sim 200 \mathrm{C}$, it is necessary to limit the spacing between the plates to a few millimeters, for the specific thermal loading estimated to be present in an optimized $100 \mathrm{~kW}$ laser. Using the parameter definitions given in Fig. 6 and in Table 3, we calculated a center-to-edge temperature gradient of $203 \mathrm{C}$ when the cell plate separation is $3 \mathrm{~mm}$, for a DPAL producing $100 \mathrm{~kW}$ output. We also calculated the Rayleigh Number, Ra, given by Eq. (1) to be 442 under these conditions, indicating that the thermally loaded gain medium is stable against the classic Bernard cell flow instability (whose threshold value for convective instability is 1100 ).

$$
\mathrm{Ra}=\mathrm{L}^{3} \rho^{2} \mathrm{~g} \beta \Delta \mathrm{T} \mathrm{C}_{\mathrm{p}}(\mu \kappa)^{-1}
$$

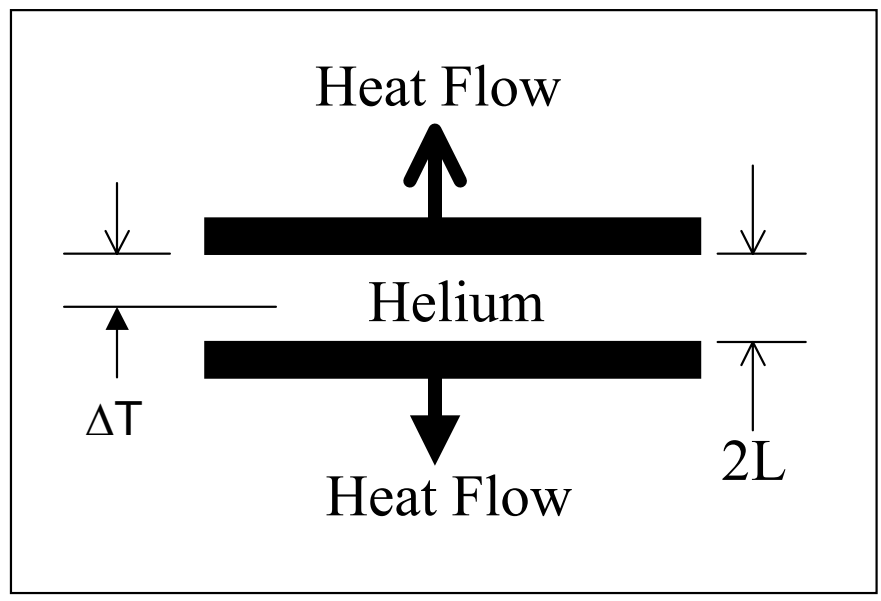

FIGURE. 6 Parameters for helium conductive cooling in a $\mathrm{kW}$ class DPAL wavelguide laser 
TABLE 3. Parameters for a $100 \mathrm{~kW}$ DPAL waveguide laser

\begin{tabular}{|l|l|}
\hline Parameter (definition) & Parameter Value \\
\hline $\mathrm{L}=$ channel half-height & $0.15 \mathrm{~cm}$ \\
\hline$\rho=$ gas density & $1.785 \mathrm{~g} /$ liter \\
\hline $\mathrm{g}=$ gravity acceleration & $980 \mathrm{~cm} / \mathrm{sec}^{2}$ \\
\hline$\beta=$ coeff. of therm expan. & $0.00367 / \mathrm{C}$ \\
\hline $\mathrm{C}_{\mathrm{p}}=$ specific heat & $1.24 \mathrm{~g} / 1$ \\
\hline$\mu=$ viscosity & 0.0002 poise \\
\hline $\mathrm{k}=$ thermal conductivity & $1.5 \mathrm{~mW} / \mathrm{cm}^{-} \mathrm{C}$ \\
\hline $\mathrm{P}_{\mathrm{p}}=$ pump flux & $50 \mathrm{~kW} / \mathrm{cm}^{2}$ \\
\hline$\Delta \lambda_{\mathrm{p}}=$ pump spectral width $(\mathrm{FWHM})$ & $2 \mathrm{~nm}$ \\
\hline $\mathrm{L}=$ channel half-height & $0.15 \mathrm{~cm}$ \\
\hline $\mathrm{P}=$ helium pressure & $10 \mathrm{~atm}$ \\
\hline$\Delta \mathrm{T}=$ ctr-to-edge temp diff. & $204 \mathrm{C}$ \\
\hline $\mathrm{Ra}=$ Rayleigh Number & 442 \\
\hline
\end{tabular}

Of course, because the index of refraction of the DPAL gain medium is dominated by the $10 \mathrm{~atm}$ of helium buffer gas, its value is quite small at $\sim 1.00036$. Moreover, for this static cell design, the variation of the index of refraction of gain medium is negative with a value of $\sim-6.7 \times 10^{-7} / \mathrm{C}$ (or about $1 / 10$ in magnitude that of most solid state gain media such as YAG). Thus, this feature offers the possibility of designing for an athermal medium condition to facilitate achievement of near-diffraction-limited beam quality at very high $\mathrm{CW}$ laser power.

We have outlined the case for potassium, rubidium, and cesium DPALs as optimum lasers for laser power beaming applications, with respect to their operating in a pure continuous-wave mode and their operating at essentially ideal wavelengths: $\mathrm{Si}$ (Cs $895 \mathrm{~nm}$; Rb $795 \mathrm{~nm}$ ) and AlGaAs (Rb $795 \mathrm{~nm}$; K $770 \mathrm{~nm}$ ). We have also described the basic DPAL architecture and outlined how power scaling to the $100 \mathrm{~kW}$ range can be approached while maintaining near diffraction-limited performance. Although at very early stage of development, it appears that the development of high power DPALs can be realized using currently available diode pump arrays. Given a projected optical-to-optical efficiency as high as $60 \%$ for a well designed DPAL, and the $\sim 50 \%$ electrical efficiency of modern diode pump arrays, we can look forward to DPAL electrical efficiencies in the $20-25 \%$ range.

\section{POWER BEAMING FOR LEO-TO-GEO MISSION}

For large laser facilities the capital costs typically dominate over operating costs. Under these circumstances desirable mission characteristics involve continuous operation or at least high duty factors. For applications to propulsion, short and rare events such as earth-to-LEO flights should be avoided. Potential longer durations but very rare flight profiles such as interplanetary missions also offer few attractions. The most attractive power beaming propulsion opportunity appears to be the lifting of satellites from LEO to GEO. The current launch rate would provide over ten launches 
per year. If the flight duration is around one month, then a power beaming system could potentially have near continuous utilization.

The primary savings in raising satellites to GEO would be the lowering of the conventional launch costs by a reduction of payloads required to be lifted to LEO. In modern launch vehicles a high efficiency second stage $\left(\mathrm{I}_{\mathrm{sp}} \sim 450 \mathrm{sec}\right)$ is used to insert the satellite into a geosynchronous transfer orbit (GTO). For a Delta IV vehicle the payload in GTO is about 0.57 of the payload capacity in LEO. A lower efficiency solid rocket $\left(\mathrm{I}_{\mathrm{sp}} \sim 290 \mathrm{sec}\right)$ is used to circularize the orbit at apogee. As a result the payload weight in GEO will be less than thirty percent of the launch vehicle's capacity for LEO. A power beaming propulsion system would have a much higher payload to LEO mass fraction.

Power beaming propulsion could be used either for the less demanding circularization task requiring a velocity change of approximately $2 \mathrm{~km} / \mathrm{sec}$ or for both tasks requiring a total change of $5.2 \mathrm{~km} / \mathrm{sec}$. These velocity changes for slow, low acceleration systems are slightly larger than for the fast impulse changes of conventional rockets. The circularization task has the additional advantage of competing against less efficient solid rocket technology.

To achieve these missions a large $(10 \mathrm{~m})$ ground based telescope would be required to beam the power to the satellite. The satellite would be in view of the telescope for only part of its orbit, particularly for low orbits. After the laser beam is converted to electrical power by the satellite solar cells, an ion or other electrical propulsion system would utilize the power. Table 4 gives the characteristics of such a system. Table 5 shows the estimated performance for the two mission options. This initial estimate ignores the complications of limited satellite visibility which would lengthen the required times.

Table 4. Power beaming system characteristics

$\begin{array}{lrll}\text { Laser power } & 125 \mathrm{~kW} & \text { Burn duration } & 1 \mathrm{month} \\ \text { Propulsion power } & 50 \mathrm{~kW} & \text { Fuel mass } & 290 \mathrm{~kg} \\ \text { Ion propulsion } & & \text { Engine mass } & 100 \mathrm{~kg} \\ \text { Specific impulse } & 3000 \mathrm{sec} & \text { Telescope diameter } & 10 \mathrm{~m} \\ \text { Thrust } & 3.3 \mathrm{~N} & \text { Receiver diameter } & >8 \mathrm{~m}\end{array}$

Table 5. Mission capabilities

$\begin{array}{lll}\text { Mission } & \text { LEO to GEO } & \text { GTO to GEO } \\ \Delta \mathrm{v} \text { required }(\mathrm{km} / \mathrm{sec}) & 5.2 \mathrm{~km} / \mathrm{sec} & 2.0 \mathrm{~km} / \mathrm{sec} \\ \text { Payload }(\mathrm{kg}) & 1420 & 4090 \\ \text { Total mass }(\mathrm{kg}) & 1810 & 4480 \\ \begin{array}{l}\text { Mass for conventional } \\ \text { rocket }\end{array} & 5070 & 7690\end{array}$

A power beaming laser of order $125 \mathrm{~kW}$ appears adequate to address many of the current propulsion requirements. Once such a laser is technically feasible, the major economic savings in launch vehicle costs would make a compelling case for rapid deployment. 


\section{ACKNOWLEDGMENTS}

This work was performed under the auspices of the U. S. Department of Energy by the University of California, Lawrence Livermore National Laboratory under Contract No. W-7405-Eng-48.

\section{REFERENCES}

1. G. A. Landis, "Solar Power for the Lunar Night”, NASA TM-102127, May, 1989.

2. G. A. Landis, "Photovoltaic Receivers for Laser beamed Power in Space", J. Propulsion and Power, $\underline{9}$ (1) 105-112 (1993)

3. D. K. Monroe, "Laser Power Beaming to Extend Lives of GSO NiCd Satellites", Laser Power Beaming, SPIE 2121, 256-263 (1994)

4. H. W. Friedman, "Near-Term Feasibility Demonstration of Laser Power Beaming", Laser Power Beaming, SPIE, 2121, 232-242 (1994)

5. G. A. Landis, M. Stavnes, S. Oleson, and J. Bozek, "Space Transfer with Ground Based Laser/Electric Propulsion”, AAIA Paper No. 92-3213, and NASA TM-106060, July 1993.

6. R. J. Glumb and H. Krier, "Concepts and Status of Laser-Supported Rocket Propulsion”, J. Spacecraft and Rockets, 21 (1) 70-79 (1984)

7. B. C. Edwards, "The Space Elevator: an Ideal Application for the Free Electron Laser", Laser and Beam Control Technologies, SPIE, 4632, 134-140 (2002)

8. B. C. Edwards and H. E. Bennett, "Space Elevator Feasibility Test Using Laser Power Beaming", Laser and Beam Control Technologies, SPIE, 4632, 141-147 (2002)

9. H. E. Bennett, "DOD and Navy Applications for Laser Power Beaming", Laser Power Beaming II, SPIE, 2376, 21-30 (1995)

10.G. W. Zeiders, "Systems Analysis on Laser Beamed Power”. NASA-CR-193206, NASA Contract H-11986D, April 1993

11.H. E. Bennett, J. D. Rather, and E. E. Montgomery IV, "Free-electron laser power beaming to satellites at China Lake, California", Laser Power Beaming, SPIE, 2121, 182-202 (1994)

12.H. E. Bennett, "Free-electron laser power beaming to satellites at China Lake, California", Nuclear Inst. and Methods in Phys. Res., A341, 124-131 (1994)

13.B. Anspaugh, R. Mueller, R. Lowe, and G, A, Landis, "Results of Illuminating Various Solar Cells with Pulsed Laser Light”, JPL Publ. 92-25, Nov. 1, 1992

14.R. Lowe, G. A. Landis, and P. Jenkins, "The Efficiency of Photovoltaic Cells Exposed to Pulsed Laser Light”, Proc. XII Space Photovoltaic Research and Technology Conf. (SPRAT XII), NASA CP 3210, 129-146, Oct., 1993

15.R. K. Jain and G. A. Landis, "Modeling of High Efficiency Concentrator Solar Cells Under Laser Pulse", Laser Power Beaming, SPIE, 2121, 264-268 (1994)

16.M. R. LaPointe and S. R. Oleson, "Low Power Ground-Based Laser Illuminatin for Electric Propulsion Applications”. NASA Contractor Report 194444, IEPC 93-208, Jan. 1994

17. W. F. Krupke, R. J. Beach, V. K. Kanz, and S. A. Payne, "Diode Pumpable Rubidium Laser", OSA TOPS ASSP, $\underline{83}, 121-125$ (2003)

18.W. F. Krupke, R. J. Beach, V. K. Kanz, and S. A. Payne, "795 nm Resonance Transition Rubidium Laser", Opt. Lett, accepted for publication, 2003

19.W. F. Krupke, “Diode Pumped Alkali Laser”, US Patent Application, US 2003/0099272 A1

20.A. T. Mattick, A. Hertzberg, R. Decher, and C. V. Lau, "High Temperature Solar Photon Engines", J. Energy, $\underline{3}$, 30-39 (1979)

21.G. J. Dunning and A. J. Palmer, "Towards a High-Temperature Solar Electric Converter”, J. Appl. Phys., 52, 7066-7091 (1981)

22.R. J. Beach, "CW Theory of Quasi-Three-Level End-Pumped Laser Oscillators”, Optics

Communications, $\underline{123}$, 385-393 (1995) 